European

Thyroid Journal
Eur Thyroid J 2013;2:252-258

DOI: $10.1159 / 000355288$
Received: May 17, 2013

Accepted after revision: August 20, 2013

Published online: November 27, 2013

\title{
Se- and S-Based Thiouracil and Methimazole Analogues Exert Different Inhibitory Mechanisms on Type 1 and Type 2 Deiodinases
}

\author{
Eddy Rijntjes $^{a} \quad$ Philip Moritz Scholz ${ }^{a} \quad$ Govindasamy Mugesh ${ }^{b} \quad$ Josef Köhrle ${ }^{a}$

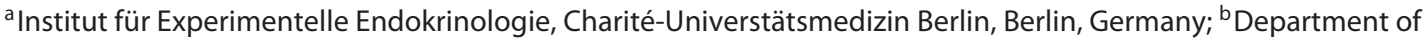 \\ Inorganic and Physical Chemistry, Indian Institute of Science, Bangalore, India
}

\section{Key Words}

Deiodinase · Propylthiouracil · Methimazole · Selenium .

Inhibitor $\cdot$ Thyrostatic compounds · Thyroid

\begin{abstract}
The thioamide anti-thyroid drugs methimazole (MMI) and propylthiouracil (PTU) play a pivotal role in the treatment of hyperthyroidism. MMl exerts its effect via inhibiting one of the key enzymes involved in synthesis of thyroid hormones (TH), thyroid peroxidase (TPO). PTU is both an inhibitor of TPO and type 1 deiodinase (D1), which catalyzes TH deiodination at both aromatic rings. In contrast, no selective inhibitors are known for type 2 deiodinase (D2) or type 3 deiodinase, which deiodinate $\mathrm{TH}$ at the phenolic or tyrosyl ring, respectively. We aimed to identify specific inhibitors for D1 or D2. New Se- and S-based PTU and MMI-like compounds have been generated. The D1 and D2 inhibiting capacity of several compounds was tested in vitro. Our data show that compounds based on a PTU and MMI backbone can differentially influence the reaction kinetics of deiodinases. For inhibition of D1, the addition of a phenyl group to the PTU backbone increases potency by at least 10 -fold over PTU. For inhibition of D2, the addition of an aromatic ring structure to $\mathrm{MMI}$ and its Se isomer increases inhibitory potency by
\end{abstract}

an order of magnitude. Furthermore, S-methylation of the $\mathrm{MMI}$ changes its reaction kinetics from non-competitive to uncompetitive with respect to the cofactor dithiothreitol. These results open perspectives for further investigations on identifying specific inhibitors of the deiodinase isoenzymes, potentially based on the addition of aromatic ring structures or alkyl groups to PTU and MMI.

Copyright $\odot 2013$ European Thyroid Association Published by S. Karger AG, Basel

\section{Introduction}

The thioamide compounds 6-n-propyl-2-thiouracil (PTU), methimazole (MMI) and carbimazole represent widely used anti-thyroid therapeutic drugs in the treatment of hyperthyroidism [1]. Their main pharmacological target is the hemoprotein thyroperoxidase (TPO), the key enzyme of thyroid hormone (TH) biosynthesis. In addition, PTU is also a strong inhibitor of the enzyme deiodinase type 1 (D1), an enzyme responsible for both 'outer' phenolic ring deiodination of L-thyroxine $\left(\mathrm{T}_{4}\right)$ yielding the major biologically active $\mathrm{TH}$, i.e. 3,5,3'-triiodo-L-thyronine $\left(\mathrm{T}_{3}\right)$, and 'inner' tyrosyl ring deiodination of $\mathrm{T}_{4}$ generating the 'inactive' $\mathrm{TH} 3,3^{\prime}, 5^{\prime}$-triiodo-L-thyro-

\begin{tabular}{ll}
\hline KARGER & $\begin{array}{l}\text { ○ 2013 European Thyroid Association } \\
\text { Published by S. Karger AG, Basel }\end{array}$ \\
E-Mail karger@karger.com & $2235-0640 / 13 / 0024-0252 \$ 38.00 / 0$ \\
www.karger.com/etj &
\end{tabular}


nine (reverse $\mathrm{T}_{3}\left(\mathrm{rT}_{3}\right)$ ). However, both MMI and PTU have unwanted side effects. Hepatoxicity in children induced by PTU for example is advocated as a call for alternate therapies $[2,3]$. Ongoing discussions about a possible relationship between the prenatal use of MMI and choanal atresia in offspring, a rare side effect of pharmacological treatment of maternal hyperthyroidism during pregnancy, raise questions about the safety of MMI [4].

Essential in the mode of action for all deiodinases is the selenocysteine residue in their catalytic center [5-8]. Additionally, cysteine and alanine residues in the catalytic center of the deiodinases seem to be pivotal in the interaction of the enzyme with $\mathrm{TH}$ and the reducing cofactors [9]. The current ping-pong kinetics model for the reaction catalyzed by D1 involves the formation of a selenenyl-iodide intermediate (enzyme-Se-I) formed by iodide transfer from $\mathrm{T}_{4}$ to the selenol group of $\mathrm{D} 1$ [10]. This reaction is followed by regeneration of the selenol group by a reaction with a thus far unidentified endogenous cofactor. In the in vitro laboratory settings for deiodinase assays 1,4-dithiothreitol (DTT) functions as a powerful cofactor. However, the D1 inhibitor PTU forms a relatively stable enzyme-Se-S-PTU complex under the release of $\mathrm{I}^{-}$, thus preventing the regeneration of the enzyme selenol group, and hence blocking the D1 activity. Additionally, gold thioglucose (GTG) competitively inhibits deiodination by interaction with the negatively charged selenolate residue of $\mathrm{D} 1$, blocking its interaction with $\mathrm{T}_{4}$. Due to the higher nucleophilicity of Se [11], it was suggested that Se analogues might form an enzyme-Se-Se analogue more effectively than the enzyme-Se-S analogue $[12,13]$, hence inhibit D1 activity even more prominently. On the other hand, the enzyme-Se-Se analogue might more easily be reduced by high levels of thiols (DTT) compared to the enzyme-Se-S-PTU complex [14-16]. In fact, the selenium analogue of PTU (PTU-Se) was quite similar, or only slightly more potent in its capacity to inhibit D1 activity compared to the classical PTU (PTU-S) $[10,12]$. This study now reports on inhibitory effects of new MMIand PTU-based S and Se analogues and their interaction with the in vitro cofactor DTT in relation to D1 activity.

Type 2 deiodinase (D2), however, which is thought to follow sequential reaction kinetics, is not nearly as susceptible for GTG and PTU inhibition as D1. The sequential reaction kinetics implies that cofactor, TH and enzyme need to interact simultaneously for the reaction to occur. One of the models for D2 kinetics is the formation of a bond between the $\mathrm{SeC}$ residue of $\mathrm{D} 2$ with $\mathrm{T}_{4}$. I is cleaved off due to binding to DTT and subsequently released as $\mathrm{I}^{-}$leaving oxidized DTT. The newly formed $\mathrm{T}_{3}$ is released from the $\mathrm{SeC}$ complex and the $\mathrm{D} 2$ is regenerated to its original form [17]. The absence of formation of an enzyme-Se-I intermediate would then explain the limited inhibition of PTU on D2 in the presence of $20 \mathrm{mM}$ DTT. Under conditions with low levels of the cofactor DTT (0.2 mM), however, the D2 becomes more sensitive to PTU [17]. This study reports on the indication that there is a shift in the mechanism of D2 kinetics with the in vitro cofactor DTT, using new MMI- and PTU-based $\mathrm{S}$ and Se analogues.

\section{Materials and Methods}

\section{General Synthesis of Selenoureas and Thioureas}

The thiourea derivatives PTU, C1, C2, and C3 were obtained from TCI Chemicals (Chennai, Tamil Nadu, India). All chemical reactions were carried out under nitrogen or argon using standard vacuum-line techniques. Solvents were purified by standard procedures and were freshly distilled prior to use. Compound C4 was synthesized from $\mathrm{N}$-methylimidazole via lithiation, followed by selenium insertion reactions as reported previously [18]. Compounds $\mathrm{C} 5-\mathrm{C} 10$ were obtained from the corresponding lithium thiolate or selenolate according to methods reported in literature [19]. For the inhibition studies, all the compounds were purified by column chromatography on an automated flash chromatography system (Biotage) by using preloaded silica cartridges.

\section{Cell Homogenates}

For deiodinase assays, cell homogenates were prepared and kept at $-80^{\circ} \mathrm{C}$ until analysis. For D1 assays pooled liver homogenates were prepared from Bl6 mice (4-20 weeks old, male and female). Livers were snap frozen in liquid nitrogen, powdered and homogenized on ice by adding 5 vol of homogenization buffer $(250$ mM saccharose, 20 mM Hepes, 1 mM EDTA, 1 mM DTT; pH 7.4). Hep-G2 cells were grown in DMEM/F12 medium containing 10\% fetal calf serum (FCS; Biochrom, Berlin, Germany). The culture medium was changed every third day. Cells were collected by trypsinization. Cells were then spun down $(800 \mathrm{~g}, 10 \mathrm{~min})$ and resuspended in homogenization buffer. Both fresh mouse liver and Hep-G2 cells were then sonicated and centrifuged $(10,000 \mathrm{~g}, 10$ $\mathrm{min})$. The pellet was dissolved in homogenization buffer. For the D2 assays, mouse thyrotroph TaT1 cells [20] were grown in DMEM/F12 medium containing 10\% FCS. $12 \mathrm{~h}$ before collection, TaT1 cells were incubated in DMEM/F12 medium in the absence of FCS. For collection the flask was rinsed with PBS. $1 \mathrm{ml}$ of homogenization buffer was added per $75-\mathrm{cm}^{2}$ flask and the cells were scraped off. The suspension was sonicated and stored for further analysis. All cells were cultured in the presence of $100 \mathrm{nM} \mathrm{Na}_{2} \mathrm{SeO}_{3}$ at $37^{\circ} \mathrm{C}$ and $5 \% \mathrm{CO}_{2}$.

\section{Deiodinase Assay}

The deiodinase assays were performed at $\mathrm{pH} 7.4$ with TaT1 (30 $\mu \mathrm{g}$ per reaction), Hep-G2 $(50 \mu \mathrm{g})$ and liver extracts $(20 \mu \mathrm{g})$ cell homogenates. DTT (2-40 mM) was the cofactor, whereas $\mathrm{rT}_{3}$ served as substrate [final concentration respectively $2 \mathrm{nM} \mathrm{rT}_{3}$ (TaT1) and 
Table 1. Molecular structure of the S and Se analogues of PTU and MMI with their molecular weights and $\mathrm{IC}_{50}$ values in the deiodinase assays

\begin{tabular}{|c|c|c|c|c|}
\hline $\begin{array}{l}\text { Com- } \\
\text { pound }\end{array}$ & $\begin{array}{l}\text { Molecular } \\
\text { weight, } \\
\text { g/mol }\end{array}$ & Structure & $\begin{array}{l}\mathrm{IC}_{50} \\
\mathrm{D} 1, \mathrm{M}\end{array}$ & $\begin{array}{l}\mathrm{IC}_{50} \\
\mathrm{D} 2, \mathrm{M}\end{array}$ \\
\hline PTU & 170.2 & & 1.70 E-06 & ND \\
\hline MMI & 114.2 & & ND & ND \\
\hline $\mathrm{C} 1$ & 142.2 & & 7.04 E-07 & $4.31 \mathrm{E}-03$ \\
\hline $\mathrm{C} 2$ & 218.3 & & 1.24 E-07 & $1.71 \mathrm{E}-04$ \\
\hline C3 & 200.2 & & 1.74 E-06 & 8.51 E-03 \\
\hline $\mathrm{C} 4$ & 320.1 & & 4.13 E-04 & $4.30 \mathrm{E}-03$ \\
\hline C5 & 128.2 & & $2.00 \mathrm{E}-03$ & 9.00 E-04 \\
\hline C6 & 175.1 & & 3.39 E-03 & 2.85 E-03 \\
\hline C7 & 204.3 & & 2.94 E-03 & 3.15 E-04 \\
\hline C8 & 251.2 & & 5.18 E-04 & 2.67 E-04 \\
\hline C9 & 330.5 & & 1.41 E-03 & 4.03 E-04 \\
\hline C10 & 424.3 & & $2.13 \mathrm{E}-02$ & 9.58 E-04 \\
\hline
\end{tabular}

Compounds C5-C10 were liquid at room temperature, whereas $\mathrm{C} 1-\mathrm{C} 4$ were solids. The compounds were purified by silica gel column chromatography using petroleum ether and ethyl acetate as eluent. Compounds were freshly dissolved in DMSO at the start of each experiment. For deiodinase assays the compounds were further diluted with $\mathrm{H}_{2} \mathrm{O}$. Assays were performed in the presence of $20 \mathrm{~mm}$ DTT as cofactor using Hep-G2 (D1) and TaT1 (D2) cell homogenates. No meaningful $\mathrm{IC}_{50}$ could be computed for PTU in the D2 assay since PTU inhibition was used to differentiate between D1 and D2 activity. ND = Not determined.
$1 \mu \mathrm{M} \mathrm{rT}{ }_{3}$ (Hep-G2 and liver)]. Incubations were optimized by adjusting incubation time and substrate such that less than $20 \%$ of the ${ }^{125} \mathrm{I}$-labeled $\mathrm{rT}_{3}$ tracer was deiodinated. $\mathrm{L}-3,3^{\prime}, 5^{\prime}-\left[{ }^{125} \mathrm{I}\right]$-triiodothyronine was purchased from PerkinElmer, $0.82 \mu \mathrm{Ci} / \mathrm{pmol}$. The addition of $\mathrm{H}_{2} \mathrm{O}$ or $1 \mathrm{mM}$ PTU (final concentration) to the reaction mixture differentiated between D1 and D2 activity. Samples were incubated for determination of deiodinase activity in the absence or presence of inhibitory compounds for $1-2 \mathrm{~h}$ in a shaking water bath at $37^{\circ} \mathrm{C}$. The reaction was stopped by placing samples on ice, instantly adding half a volume of stop solution $(10 \%$ BSA, $0.01 \mathrm{~mm}$ PTU), and 3 vol of cold $10 \%$ trichloric acid. Samples were centrifuged ( $5 \mathrm{~min}, 10,000 \mathrm{~g}$ ), and the supernatant was eluted over a Dowex-50 WX-2 column (Bio-Rad). The ${ }^{125} \mathrm{I}$ in the eluate was counted using a gamma counter (1277 Gammamaster; LKB Wallac, Turku, Finland). The difference in counts, corrected for background, between the eluates incubated in the absence and presence of PTU was attributed to D1 activity. The remaining activity was assigned to D2 activity. All experiments were done in triplicates and repeated at least 3 times with different cell collections.

\section{Results}

PTU (-S) is thought to form a relatively stable enzymeSe-S-PTU complex with the active site selenolate of D1, blocking D1 activity $\left(\mathrm{IC}_{50}=1.7 \mu \mathrm{M}\right.$ in the presence of 20 mM DTT). Our results show that the PTU-like compounds C1 (5-methyl-2-thiouracil) and C2 (6-benzyl2-thiouracil) have an even lower $\mathrm{IC}_{50}$ than PTU, making them more potent inhibitors of D1 activity. The third PTU-like compound, C3, has an $\mathrm{IC}_{50}$ comparable to PTU (table 1).

In general, the $\mathrm{N}$-methylimidazoles were 1,000 -fold less potent in inhibiting the D1 activity compared to the PTU-derived compounds. The $\mathrm{IC}_{50}$ values were comparable between the pairs of Se- and S-based MMI analogues which only differed in their Se or S moiety (C5 vs. C6, C7 vs. C8, C9 vs. C10; table 1).

The D1 is assumed to follow ping-pong reaction kinetics with $\mathrm{rT}_{3}$ as substrate, and DTT as cofactor. This implies that D1 interacts with the cofactor DTT after formation of the enzyme-Se-I complex. If Se- and S-based thiouracil and MMI analogues interfere with DTT-dependent regeneration of active enzyme from the E-Se-I complex intermediate, D1 activity and reaction kinetics might be affected.

In general the type of inhibition is derived from the change in the maximum velocity $\left(\mathrm{V}_{\max }\right)$ of the enzymatic reaction and the Michaelis constant $\mathrm{K}_{\mathrm{m}}$, with varying cofactor and inhibitor concentrations. If an increase in cofactor concentration can overcome the decreased velocity induced by the inhibitor, thus changing the $\mathrm{K}_{\mathrm{m}}$, this is 


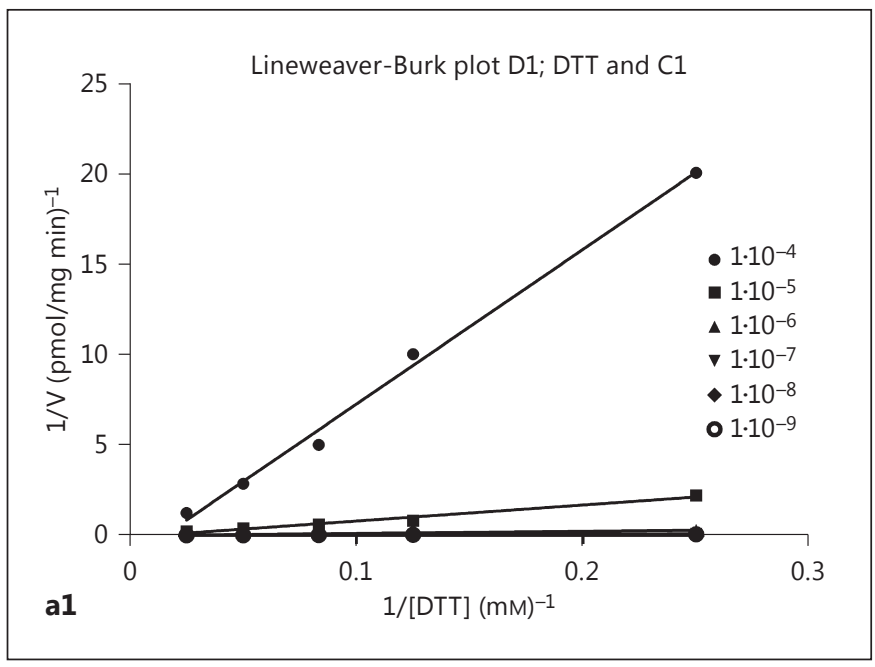

Fig. 1. Representative Lineweaver-Burk (1/V vs. 1/[DTT]) (a) and Eadie-Hofstee (V vs. V/[DTT]) (b) plots for the effects of increasing concentrations of compound $\mathrm{C} 1$ on the D1 activity of liver homogenates at different concentrations of cofactor DTT. Noncompetitive interaction of the compounds with DTT will show as parallel lines in both plots. In the Lineweaver-Burk plot, C1 shows competitive reaction kinetics since the lines are not parallel, yet cross at the same point on the $y$-axis. For the lower concentration range, the Eadie-Hofstee plot points to a more non-competitive type of reaction kinetics. Each data point reflects the mean values of triplicate measures of a representative experiment. The solid lines are extrapolates generated by linear regression fits.

called competitive inhibition. The lines in the Lineweaver-Burk (1/V) vs. 1/[cofactor] (1/[DTT]) and in the EadieHofstee (V vs. V/[cofactor]) should cross at the y-axis. If the increase in cofactor concentration does not change the effect of the inhibitor, the interaction is non-competitive $\left(V_{\max }\right.$ is decreased whereas $\mathrm{K}_{\mathrm{m}}$ remains unaffected, rendering parallel lines in the Eadie-Hofstee plot). Uncompetitive inhibition is defined as that the inhibitor will combine with the enzyme-substrate-cofactor complex only, and not with the enzyme directly. The $\mathrm{V}_{\max }$ and $\mathrm{K}_{\mathrm{m}}$ are equally affected, resulting in a set of parallel lines in the Lineweaver-Burk plot.

To test the kinetics of the deiodinases, the enzyme was incubated in the presence of various concentrations of the thiouracil and MMI analogues, respectively, and different concentrations of the cofactor DTT. For none of the ana-
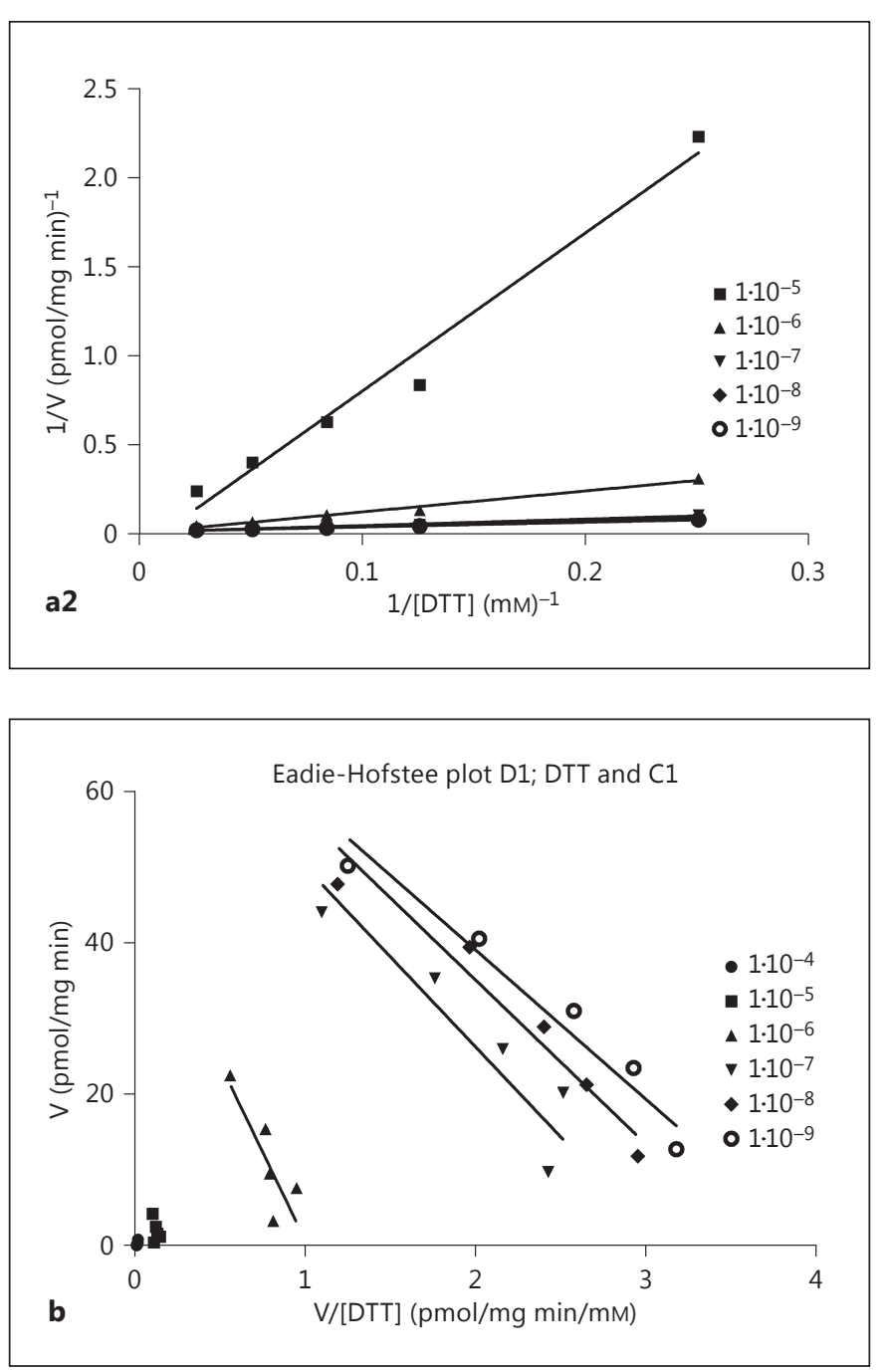

logues the background iodide release at the highest concentration (1-10 $\mathrm{mM}$ ) was different from that observed for PTU within the DTT concentration range used (2-40 $\mathrm{mM})$.

The $\mathrm{V}_{\max }$ of the two substrate $\mathrm{D} 1$ reactions depends on the concentration of the cofactor DTT, the reaction occurs faster at a higher concentration of DTT. The primary plots of enzyme kinetic data for compound $\mathrm{C} 1$ on D1 activity show a mixed type of inhibition (fig. 1a, b). When the compound is administered at concentrations below the $\mathrm{IC}_{50}$, lines almost run parallel, yet seem to point towards a similar point on the $\mathrm{x}$-axis (fig. $1 \mathrm{~b}$, non-competitive). On the other hand, concentrations higher than or around the $\mathrm{IC}_{50}$ seem to follow a competitive type of interaction with varying levels of the cofactor DTT (fig. 1a, b). The two other compounds tested on this wide DTT 

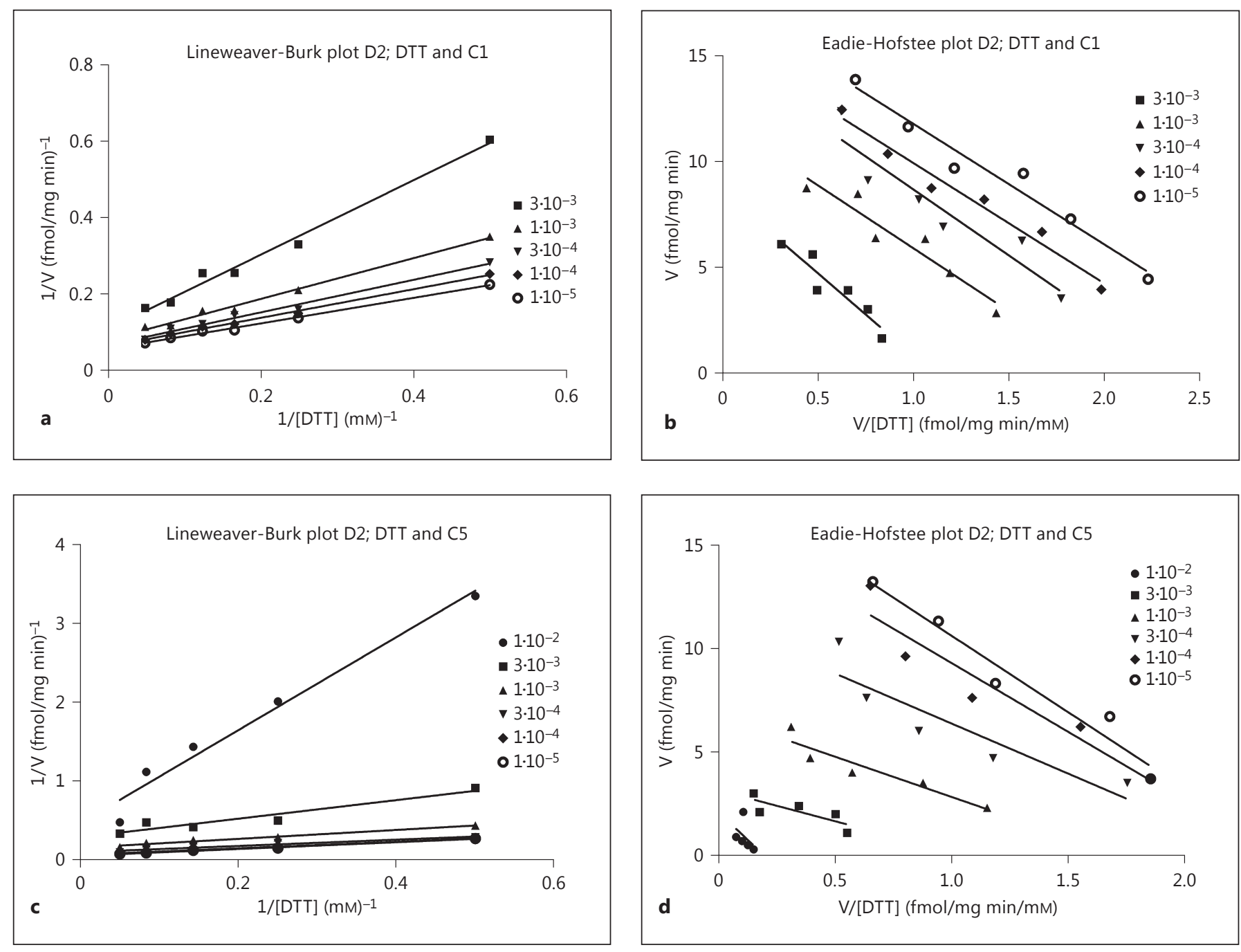

Fig. 2. Representative Lineweaver-Burk (1/V vs. 1/[DTT]) (a, c) and Eadie-Hofstee (V vs. V/[DTT]) (b, d) plots for the effects of increasing concentrations of compound C1 (a, b) and compound C5 (c, d) on the D2 activity of TaT1 cell homogenates at different concentrations of cofactor DTT. C1 is a non-competitive inhibitor of the D2 reaction, whereas $\mathrm{C} 5$ has uncompetitive inhibition behavior in the reaction. Each data point reflects the mean values of triplicate measures of a representative experiment. The solid lines are extrapolates generated by linear regression fits.

range, $\mathrm{C} 4$ and $\mathrm{C} 9$, which had $\mathrm{IC}_{50}$ values 1,000-fold higher than $\mathrm{C} 1$, were non-competitive.

For D1 inhibition the PTU-like thiourea compounds C1-C3 were more potent inhibitors than the MMI-like compounds. However, the $\mathrm{IC}_{50}$ of $\mathrm{D} 2$ inhibition by the compounds is in the $10^{-4}-10^{-3} \mathrm{M}$ range for both PTUand MMI-like compounds. With the exception of C4, all MMI-like compounds had $\mathrm{IC}_{50}$ values higher for D2 compared to D1 in the presence of 20 mM DTT (table 1). To test the reaction kinetics, the compounds $\mathrm{C} 1$ and $\mathrm{C} 5$ were incubated with a fixed level of $\mathrm{rT}_{3}$ under a wide range of cofactor DTT concentrations. Kinetic plots revealed $\mathrm{C} 1$ to be a non-competitive D2 inhibitor. The Eadie-Hofstee plot shows an equal slope of the lines, suggesting cofactor DTT is not affected in its interaction with the enzyme-Se- $\mathrm{T}_{3}$ complex. With increasing concentrations of compound $\mathrm{C} 1$, the maximum rate of the reaction is decreased (fig. 2a, b).

However, for compound C5 the decreasing slope of the Eadie-Hofstee plot in combination with the decreasing maximum rate of the reaction with increasing concentrations of $\mathrm{C} 5$ indicates uncompetitive inhibi- 
tion. This can also be derived from the LineweaverBurk plots which generally show a parallel set of lines with the exception of the $10-\mathrm{mM}$ concentration of $\mathrm{C} 5$ (fig. 2c, d).

\section{Discussion}

The regeneration of deiodinases-selenol groups after interaction with $\mathrm{TH}$ is essential for the functionality of deiodinases, and is thus a potential target for inhibition. The endogenous cofactor responsible for this regeneration has thus far not been identified. However, in the presence of the cofactor for laboratory settings, i.e. DTT, a functional D1 is not regenerated during co-incubation with PTU. We have now identified PTU- and MMI-derived compounds which are more potent than PTU and MMI in inhibition of D1, and even D2.

Our results reveal that substitution of the $n$-propyl group of PTU by the small methyl group on the 5-position renders a more potent D1 inhibitor in liver homogenates. In contrast, isomeric 5-propyl-2-thiouracil seemed to be only a slightly more efficient inhibitor than the classical 6-propyl-2-PTU [21]. In an earlier study the methyl substitution on the 6-position of PTU was shown to have similar inhibitory capacities as PTU in rat liver microsomes [10, 21]. Interestingly, in our current study the substitution of the $n$-propyl residue by an aromatic ring on the 6-position reveals the highest potency in inhibiting D1. The polar substituent in $\mathrm{C} 3$ on the 5-position is not more effective than $n$-propyl in PTU and weaker than the non-polar methyl in $\mathrm{C} 1$, although more potent than the 5-carboxyl substituent in earlier studies [21].

Previous studies on D1 inhibition have shown that PTU is competitive with DTT [10], both supposedly competing for interaction with the enzyme-Se-I complex. Our current study shows that compound $\mathrm{C} 1$ has mixed reaction kinetics, though it competitively inhibits the DTT effect around its $\mathrm{IC}_{50}$. This suggests that the 5-methyl group is able to avert DTT from interacting with the enzyme-Se-I complex. Furthermore, our results suggest the binding site in D1 adopts preferentially hydrophobic substituents in PTU analogues and provides space for an additional aromatic ring.

In contrast to PTU, MMI concentrations up to $0.3 \mathrm{mM}$ have not been shown effective in inhibition of deiodinases at all. The seleno-analogue of MMI, methylselenoimidazole, however, has proven to be a slightly better inhibitor, although even at a dose of $0.3 \mathrm{mM}$ only a $28 \%$ inhibition of the D1 activity was found [22]. Roy and Mugesh [14]

Se- and S-Based Deiodinase Inhibitors showed that this methylselenoimidazole is not stable in air and easily oxidizes to its diselenide (C4). In our hands the coupling of two methylselenoimidazole molecules via their selenium, C4, showed to be most potent with an $\mathrm{IC}_{50}$ of approximately $0.4 \mathrm{mM}$, hence better than its precursor. However, under the presence of DTT in the assay mixture, the $\mathrm{C} 4$ could be reduced to selenoimidazole. Addition of a methyl (C5) or phenyl (C7) on the sulfide group of MMI resulted in inefficient derivatives. In contrast, addition of a spacious phenyl (C8) on the relatively larger and more polarizable seleno group resulted in a 7 times more potent inhibition of D1 activity as compared to the addition of the methyl group (C6). The new compound where two selenoimidazoles are linked to a phenyl, thus increasing the size of the molecule even further, did not result in a compound with good inhibiting capacities. In general, both S- and Se-based MMI derivatives did not prove to be efficient in deiodinase inhibition.

For inhibition of D2 thus far, no inhibitor has been identified in the micromolar range other than GTG, which irreversibly inhibits deiodinases by interaction with negatively charged selenolate. Supposedly this atom only becomes available for interaction with GTG after interaction with TH and DTT. As for D1, C2 has the highest potency in inhibiting the D2 of our PTU derivatives. Addition of an aromatic ring structure to MMI and its Se isomer was most successful in inhibiting D2. These molecules (C7 and C8) might resemble TH more closely, whereas, in comparison, the methyl-MMI variants (C5 and C6) are rather small, and the $\mathrm{C} 9$ and $\mathrm{C} 10$ with two MMI bound to a phenyl residue in the meta-position are rather voluminous.

In both the PTU-based $\mathrm{C} 1$ and MMI-based C5 compounds, a methyl group was added to the original molecule of which these compounds were derived. The mode of inhibition of D2, however, is different. C1 is a noncompetitive inhibitor, whereas $\mathrm{C} 5$ was uncompetitive around its $\mathrm{IC}_{50}$. This implies that $\mathrm{C} 1$ is able to shift the enzyme into an inactive form. The potential change in structure and shape of D2 imposed by C1 will result in decreased velocity of the reaction and binding of substrate and cofactor. Hence, increasing the amount of cofactor will not reduce the inhibiting capacity of $\mathrm{C} 1$. The mode of inhibition by compound C5 is different, since in case of uncompetitive inhibition, C5 is thought to interact with the enzyme-substrate complex. $\mathrm{C} 5$ would then increase D2 affinity to its substrate and cofactor and decrease reaction velocity. The presence of these different modes of inhibition suggests there are multiple pathways to inhibit the D2 activity. 
Our data show that PTU- and MMI-based compounds can differentially influence the reaction kinetics of deiodinases. For D1 inhibition, addition of a phenyl group to the PTU backbone proves to be at least 10-fold more efficient than PTU. In D2 inhibition, addition of an aromatic ring structure to $\mathrm{MMI}$ and its Se isomer was most successful. The $S$ versus Se molecule pairs did not show clear differences in inhibiting capacity. For inhibition of TPO however, the MMI variant for which the $S$ has been replaced by Se influences the reaction by reducing $\mathrm{H}_{2} \mathrm{O}_{2}$, whereas MMI appears to interact with the enzyme [23]. Interestingly, its diselenide (C4) tested in a model for TPO activity by Roy and Mugesh [23] did not show any noticeable inhibition, opening up possibilities in identification of more specific and deiodinase isozyme-selective deiodinase inhibitors which lack TPO inhibition. Similar differences of S versus Se in the mechanism of action of the inhibition of deiodinase could be demonstrated in the cur- rent study. These results open perspectives for further investigations on identifying specific inhibitors of the deiodinase, potentially based on the addition of aromatic ring structures to $\mathrm{S}$ or Se PTU and MMI derivatives.

\section{Acknowledgements}

The authors thank Dr. Gouriprasanna Roy for his help in synthesizing some of the sulfur- and selenium-based compounds. The authors gratefully acknowledge Dr. Kostja Renko and Franziska Wohlgemuth for stimulating discussions and expert assistance.

This work is supported by grants from the Deutsche Forschungsgemeinschaft (DFG Graduiertenkolleg 1208, TP3 to J. Köhrle and U. Schweizer), EnForCé and the Charité-Universitätsmedizin Berlin to J. Köhrle.

\section{Disclosure Statement}

The authors have no conflicts of interest to disclose.

\section{References}

1 Emiliano AB, Governale L, Parks M, Cooper DS: Shifts in propylthiouracil and methimazole-prescribing practices: antithyroid drug use in the United States from 1991 to 2008. J Clin Endocrinol Metab 2010;95:2227-2233.

-2 Rivkees SA, Mattison DR: Propylthiouracil hepatoxicity in children and recommendations for discontinuation of use. Int J Pediatr Endocrinol 2009;2009:132041.

-3 Rivkees SA, Mattison DR: Ending propylthiouracil-induced liver failure in children. N Engl J Med 2009;360:1574-1575.

4 Barbero P, Valdez R, Rodriguez H, Tiscornia C, Mansilla E, Allons A, Coll S, Liascovich R: Choanal atresia associated with maternal hyperthyroidism treated with methimazole: a case-control study. Am J Med Genet A 2008; 146A:2390-2395

5 Arthur JR, Nicol F, Beckett GJ: Hepatic iodothyronine $5^{\prime}$-deiodinase. The role of selenium. Biochem J 1990;272:537-540.

-6 Behne D, Kyriakopoulos A, Meinhold H, Kohrle J: Identification of type I iodothyronine $5^{\prime}$-deiodinase as a selenoenzyme. Biochem Biophys Res Commun 1990;173:11431149 .

-7 Salvatore D, Harney JW, Larsen PR: Mutation of the Secys residue 266 in human type 2 selenodeiodinase alters ${ }^{75} \mathrm{Se}$ incorporation without affecting its biochemical properties. Biochimie 1999;81:535-538.

$\checkmark 8$ Buettner C, Harney JW, Larsen PR: The $3^{\prime}$-untranslated region of human type 2 iodothyronine deiodinase MRNA contains a functional selenocysteine insertion sequence element. J Biol Chem 1998;273:33374-33378.
-9 Kuiper GG, Kester MH, Peeters RP, Visser TJ: Biochemical mechanisms of thyroid hormone deiodination. Thyroid 2005;15:787-798.

10 Visser TJ, Kaptein E, Aboul-Enein HY: Selenouracil derivatives are potent inhibitors of the selenoenzyme type I iodothyronine deiodinase. Biochem Biophys Res Commun 1992; 189:1362-1367.

11 Hondal RJ, Marino SM, Gladyshev VN: Selenocysteine in thiol/disulfide-like exchange reactions. Antioxid Redox Signal 2013;18: 1675-1689.

12 Taurog A, Dorris ML, Hu WX, Guziec FS Jr: The selenium analog of 6-propylthiouracil. Measurement of its inhibitory effect on type I iodothyronine deiodinase and of its antithyroid activity. Biochem Pharmacol 1995;49: 701-709.

13 Gromer S, Johansson L, Bauer H, Arscott LD, Rauch S, Ballou DP, Williams CH Jr, Schirmer RH, Arner ES: Active sites of thioredoxin reductases: why selenoproteins? Proc Natl Acad Sci USA 2003;100:12618-12623.

14 Roy G, Mugesh G: Selenium analogues of antithyroid drugs - recent developments. Chem Biodivers 2008;5:414-439.

15 Manna D, Mugesh G: Regioselective deiodination of thyroxine by iodothyronine deiodinase mimics: an unusual mechanistic pathway involving cooperative chalcogen and halogen bonding. J Am Chem Soc 2012;134:4269-4279.

16 Manna D, Mugesh G: Deiodination of thyroid hormones by iodothyronine deiodinase mimics: does an increase in the reactivity alter the regioselectivity? J Am Chem Soc 2011;133: 9980-9983.
17 Kuiper GG, Klootwijk W, Visser TJ: Substitution of cysteine for a conserved alanine residue in the catalytic center of type II iodothyronine deiodinase alters interaction with reducing cofactor. Endocrinology 2002;143: 1190-1198.

18 Roy G, Nethaji M, Mugesh G: Biomimetic studies on anti-thyroid drugs and thyroid hormone synthesis. J Am Chem Soc 2004;126: 2712-2713.

19 Roy G, Mugesh G: Anti-thyroid drugs and thyroid hormone synthesis: effect of methimazole derivatives on peroxidase-catalyzed reactions. J Am Chem Soc 2005; 127:1520715217.

20 Yusta B, Alarid ET, Gordon DF, Ridgway EC, Mellon PL: The thyrotropin $\beta$-subunit gene is repressed by thyroid hormone in a novel thyrotrope cell line, mouse TaT1 cells. Endocrinology 1998;139:4476-4482.

21 Visser TJ, van Overmeeren E, Fekkes D, Docter R, Hennemann G: Inhibition of iodothyronine $5^{\prime}$-deiodinase by thioureylenes; structure-activity relationship. FEBS letters 1979; 103:314-318.

22 Taurog A, Dorris ML, Guziec LJ, Guziec FS Jr: The selenium analog of methimazole. Measurement of its inhibitory effect on type I $5^{\prime}$-deiodinase and of its antithyroid activity. Biochem Pharmacol 1994;48:1447-1453.

23 Roy G, Mugesh G: Bioinorganic chemistry in thyroid gland: effect of antithyroid drugs on peroxidase-catalyzed oxidation and iodination reactions. Bioinorg Chem Appl 2006: 23214. 